BMJ Open Diabetes

Research \& Care

\section{Glucagon-like peptide 1 agonists for treatment of patients with type 2 diabetes who fail metformin monotherapy: systematic review and meta-analysis of economic evaluation studies}

To cite: Bagepally BS, Chaikledkaew U, Gurav YK, et al. Glucagon-like peptide 1 agonists for treatment of patients with type 2 diabetes who fail metformin monotherapy: systematic review and meta-analysis of economic evaluation studies. BMJ Open Diab Res Care 2020;8:e001020. doi:10.1136/ bmjdrc-2019-001020

- Additional material is published online only. To view, please visit the journal online (http://dx.doi.org/10.1136/ bmjdrc-2019-001020).

Received 4 November 2019 Revised 26 February 2020 Accepted 8 June 2020
Check for updates

(C) Author(s) (or their employer(s)) 2020. Re-use permitted under CC BY. Published by BMJ.

For numbered affiliations see end of article.

Correspondence to Dr Usa Chaikledkaew; usa.chi@mahidol.ac.th

\section{ABSTRACT}

Objectives To conduct a systematic review and metaanalysis and to pool the incremental net benefits (INBs) of glucagon-like peptide 1 (GLP1) compared with other therapies in type 2 diabetes mellitus (T2DM) after metformin monotherapy failure.

Research design and methods The study design is a systematic review and meta-analysis. We searched MEDLINE (via PubMed), Scopus and Tufts Registry for eligible cost-utility studies up to June 2018, adhering to the Preferred Reporting Items for Systematic Reviews and Meta-Analyses guideline. We conducted a systematic review and pooled the INBs of GLP1s compared with other therapies in T2DM after metformin monotherapy failure. Various monetary units were converted to purchasing power parity, adjusted to 2017 US\$. The INBs were calculated and then pooled across studies, stratified by level of country income; a random-effects model was used if heterogeneity was present, and a fixed-effects model if it was absent. Heterogeneity was assessed using $Q$ test and $\mathrm{I}^{2}$ statistic.

Results A total of 56 studies were eligible, mainly from high-income countries (HICs). The pooled INBs of GLP1s compared with dipeptidyl peptidase-4 inhibitor (DPP4i) $(n=10)$, sulfonylureas $(n=6)$, thiazolidinedione (TZD) $(n=3)$, and insulin $(\mathrm{n}=23)$ from HICs were US\$4012.21 $(95 \% \mathrm{Cl}$ US\$-571.43 to US\$8595.84, $\left.\left.\right|^{2}=0 \%\right)$, US\$3857.34 (95\% CI US\$-7293.93 to US\$15 008.61, $\left.\left.\right|^{2}=45.9 \%\right)$, US $\$ 37$ 577.74 (95\% CI US\$-649.02 to US\$75 804.50, I $\left.^{2}=92.4 \%\right)$ and US\$14 062.42 (95\% CI US\$8168.69 to US\$19 $956.15, I^{2}=86.4 \%$ ), respectively. GLP1s were statistically significantly cost-effective compared with insulins, but not compared with DPP4i, sulfonylureas, and TZDs. Among GLP1s, liraglutide was more cost-effective compared with lixisenatide, but not compared with exenatide, with corresponding pooled INBs of US\$4555.09 (95\% Cl US $\$ 3992.60$ to US\$5117.59, $\left.\left.\right|^{2}=0\right)$ and US\$728.46 $(95 \% \mathrm{Cl}$ US $\$-1436.14$ to US $\$ 2893.07, I^{2}=0$ ), respectively. Conclusion GLP1 agonists are a cost-effective choice compared with insulins, but not compared with DPP4i, sulfonylureas and TZDs.

PROSPERO registration number CRD42018105193.

\section{Significance of this study}

What is already known about this subject?

- Glucagon-like peptide 1 (GLP1) agonists are clinically effective in treating patients with type 2 diabetes mellitus (T2DM) who fail metformin monotherapy.

- Several economic evaluation studies, along with systematic reviews of the cost-effectiveness of GLP1 agonists, have already been conducted, but these have only been descriptive and results have been conflicting.

What are the new findings?

- We synthesized quantitative evidence of the costeffectiveness of GLP1 agonists using a novel methodological approach.

- GLP1 agonists were significantly cost-effective compared with insulins but were not as cost-effective as dipeptidyl peptidase-4 inhibitor (DPP4i), sulfonylureas and thiazolidines in high income countries.

- Among GLP1 agonists, liraglutide was more costeffective compared with lixisenatide, but not compared with exenatide.

How might these results change the focus of research or clinical practice?

- This study provides a novel approach to conducting a meta-analysis of economic evaluation studies.

- GLP1 drugs could be a better choice, compared with insulins, in treating patients with T2DM after metformin monotherapy failure, but not compared with other second-line drugs that is, DPP4i, sulfonylureas and thiazolidines.

\section{INTRODUCTION}

Type 2 diabetes mellitus (T2DM) accounts for $\sim 12 \%$ of the global health expenditure ${ }^{1}$ or US $\$ 850$ billion per year. ${ }^{1}$ Its complications place a large social and financial burden on patients, families, and healthcare systems globally, ${ }^{2}$ leading to marked morbidity and 
mortality worldwide. ${ }^{2}$ Therefore, T2DM treatments aim to reduce long-term complications and mortality through glycaemic control. ${ }^{3}{ }^{4}$ Pharmacotherapy guidelines suggest that metformin should be used as initial monotherapy and that second-line agents should be added if metformin monotherapy fails to maintain glycaemic control. Second-line agents include sulfonylurea, thiazolidinedione (TZD), dipeptidyl peptidase-4 inhibitor (DPP4i), sodium glucose co-transporter 2 (SGLT2) inhibitor, glucagon-like peptide 1 (GLP1) receptor agonist, and insulin. ${ }^{5}$

Recent network meta-analyses ${ }^{6} 7$ found that GLP1 agonists were not significantly different in terms of glycaemic control, mortality or safety compared with other antidiabetic drugs. However, the American Association of Clinical Endocrinologists ${ }^{8}$ suggests that GLP1s (ie, exenatide, liraglutide, dulaglutide, lixisenatide, albiglutide and semaglutide) should be preferentially used as second-line drugs added to metformin in patients who fail metformin monotherapy.

Current reviews of economic studies have been conducted but have some limitations, including providing only descriptive summaries ${ }^{9-15}$ and conducting no systematic searches. ${ }^{91215}$ In addition, they considered only cost of illness, burden of illness, or clinical effectiveness, ${ }^{1012-14}$ but not cost-effectiveness. None of these studies synthesized or pooled economic outcome measures, which would indicate overall cost-effectiveness of the interventions. Such information would be of immense help for decision making in countries where there is a lack of costeffectiveness evidence or where there is limited capacity to generate such evidence.

Meta-analysis of economic evaluation studies was first developed by Crespo et al, ${ }^{16}$ and our research teams have recently further developed their methods to cover all aspects of meta-analysis. ${ }^{910}$ The incremental net benefit (INB) is calculated by multiplying willingness to pay (WTP) (per unit) and change in effectiveness (in units) and then subtracting the difference in costs; this estimate of INB is then pooled across studies, taking into account within-study and between-study variations. However, individual studies are conducted in different countries where WTP is different. Therefore, pooling INBs should be performed while stratifying by level of country income according to the World Bank classification. ${ }^{17} 18$ Positive and negative INBs refer to cost-effectiveness and noncost-effectiveness, respectively.

Therefore, this systematic review and meta-analysis was conducted to pool the INBs of GLP1s compared with other antidiabetic treatments in patients who failed metformin monotherapy, stratified by the level of country income.

\section{METHODS}

We followed the Preferred Reporting Items for Systematic Reviews and Meta-Analysis Protocols, ${ }^{11}$ and the protocol was registered at PROSPERO (CRD42018105193).

\section{Data sources and search strategy}

Searching was performed in PubMed, Scopus, the Cochrane Central Register of Controlled Trials, Wiley Library, ProQuest, and the Cost-effective Analysis Registry $^{12}$ by Tufts Medical Center, from inception to June 2018 (see online supplementary appendix I). Economic evaluation studies were eligible if they met all the following inclusion criteria: patients with T2DM who failed metformin monotherapy, comparison of GLP1s with any second-line drug, and report of any economic outcomes, including incremental cost-effectiveness ratio (ICER), quality-adjusted life years (QALY), or INB. Studies related to clinical effectiveness, cost/burden of illness, reviews, or multiple publications were excluded.

\section{Data extraction and risk of bias assessment}

An a priori data extraction form was constructed consisting of study/patient characteristics, intervention, economic outcomes/parameters, the methods used, and data for pooling. For the economic parameters, cost, C, or incremental/delta costs, $\Delta \mathrm{C}$; clinical effectiveness, $\mathrm{E}$, or its incremental/delta, $\Delta \mathrm{E}$; ICERs; measures of dispersion (ie, SD, SE, or $95 \% \mathrm{CI}$ ); and WTP threshold, K, were extracted. The cost-effective (CE) plane plotting $\Delta \mathrm{C}$ and $\Delta \mathrm{E}$ was also retrieved. Our intervention of interest was any GLP1, and the comparator was any other secondline antidiabetic agent. Two reviewers (BSB and YKG) independently extracted the data; any disagreement was resolved by consensus with the senior author (AT).

Risk of bias was assessed using the modified Economic Evaluations Bias checklist, ${ }^{13}$ considering overall biases (11 items) and biases from model-specific aspects, that is, structure (four items), data (six items), and internal consistency (one item). Each item was graded as yes, partly, unclear, no, or not applicable.

\section{Outcome of interest}

The primary outcome of interest was INB ${ }^{14}{ }^{16}$ which was calculated as detailed in online supplementary appendix II. Since all monetary units were reported in different currencies (ie, US\$, €, £, and $¥$ ) and at different time points (years), they were converted to purchasing power parity (PPP), adjusted to US\$ for the year 2017 before calculating INB (see example in online supplementary appendix II).

\section{Data preparation}

To calculate the INB and its variance, means along with dispersions (SD, SE, and $95 \% \mathrm{CI}$ ) of $\Delta \mathrm{C}$ and $\Delta \mathrm{E}$ were required. However, economic studies reported different parameters; therefore, five scenarios were designed to deal with data as follows. ${ }^{9} 10$

\section{Scenario 1}

Studies reported means, along with measures of dispersion for costs, outcomes, $\Delta \mathrm{C}, \Delta \mathrm{E}$, and ICER. The INB was estimated accordingly to equations (1), (2) and (3) as detailed in online supplementary appendix II. 
Scenario 2

Studies reported ICER, along with its 95\% CIs. The variance of ICER was calculated as $U L_{\text {ICER }}=\mu_{\text {ICER }}+1.96 S E_{\text {ICER }}$. For model-based analyses, costs and QALYs were derived from simulated patients with infinite sample size; thus, the square of SD and SE were taken as the variance without considering the sample size. The mean and variance of INB were calculated using equations (2) and (3) in online supplementary appendix II.

\section{Scenario 3}

Studies reported means, along with any of $95 \%$ CI, SD or SE of costs, outcomes, or $\Delta \mathrm{C} / \Delta \mathrm{E}$, but did not provide the ICER and its variance. Data for $\Delta \mathrm{C}$ and $\Delta \mathrm{E}$ were then simulated using Monte Carlo with 1000 simulations. A gamma distribution was used for $\Delta \mathrm{C}$, and normal distribution was used for $\Delta \mathrm{E}$. The mean and variance of INB were then calculated using equations (1) and (4) in online supplementary appendix II.

\section{Scenario 4}

Studies did not report any measure of dispersion but provided the $\mathrm{CE}$ plane graph (ie, a scatter plot of $\Delta \mathrm{C}$ and $\Delta \mathrm{E}$ on $\mathrm{Y}$ and $\mathrm{X}$ axis) as part of a probabilistic sensitivity analysis (PSA) analysis. Data for $\Delta \mathrm{C}$ and $\Delta \mathrm{E}$ were extracted from the $\mathrm{CE}$ plane using WebPlotDigitizer software V.4.1. ${ }^{15}$ The mean of the $\Delta \mathrm{C}$ and $\Delta \mathrm{E}$, along with their variances and covariances were estimated, leading to an estimated INB and its variance using equations (1) and (4) in online supplementary appendix II.

\section{Scenario 5}

Studies reported means of costs, outcomes, $\Delta \mathrm{C}, \Delta \mathrm{E}$, or ICER, but reported neither the dispersion nor the CE plane graph. The dispersions were taken from other studies that had reported/simulated data with the following criteria:

- Their ICERs were similar, for example, $\pm 50 \%$ to $75 \%$.

- They were similar in intervention, comparator, time period, and country region.

- They were in the same level of country income, with similar model inputs (ie, discounting and time horizon).

- If there was more than one study that met the criteria, the average of the variances of those studies was used.

\section{Statistical analysis}

Each INB and its variance were calculated as per the approaches described previously. INBs were then pooled across studies stratified by low-income countries (LICs), lower-income to middle-income countries (LMICs), upper-income to middle-income countries (UMICs) and high-income countries (HICs) as per the World Bank classification. ${ }^{8}$ Meta-analysis was applied to pool the INBs ${ }^{1016}$ using a random-effects model if heterogeneity was present (ie, $\mathrm{I}^{2} \geq 25 \%$ or $\mathrm{p}$ value of Cochrane- $\mathrm{Q}<0.1$ ); otherwise, a fixed-effects model was used (see more details in online supplementary appendix II). Sources of heterogeneity were explored using metaregression by considering covariables (ie, time horizon, discount rate, thresholds, and source of effectiveness measure) in the model oneby-one. If the $\mathrm{I}^{2}$ was decreased by $50 \%$ or more, such covariables were considered a source of heterogeneity. Sensitivity or subgroup analysis was performed where appropriate. Publication bias was assessed using funnel plots and Egger's test; any sources of asymmetry were explored using contour-enhanced funnel plots. All data were prepared using Microsoft Excel V.2016 and were analyzed by STATA software V.14. ${ }^{17}$ Two-sided $\mathrm{p}<0.05$ was considered statistically significant except for the heterogeneity test, in which $\mathrm{p}<0.10$ was used.

\section{RESULTS}

Of the 864 identified studies, 56 studies were eligible for the meta-analysis (see figure 1). From the 56 studies, 82 comparisons were assessed, including GLP1 versus DPP4i $(n=10)^{18-27}$; GLP1 versus sulfonylureas $(n=7)^{20} \quad 25-30$; GLP1 versus thiazolidines $(\mathrm{n}=3)^{21} 30$ 31; GLP1 versus insulins ( $\mathrm{n}=27,23 \mathrm{HICs}^{19}{ }^{30-52}$ and $3 \mathrm{UMICs}^{53-55}$ ); GLP1 versus insulin plus DPP4i $(n=2),{ }^{45}$ or insulin plus sulfonylureas $(\mathrm{n}=2),{ }^{52}{ }^{57}$ GLP1 versus insulin plus GLP1 $(n=5)^{3642465558}$ and insulin degludec/liraglutide (IDegLira) versus insulin $(n=7) .^{34-3642464859}$ Among GLP1s, treatment comparisons included liraglutide versus exenatide $(\mathrm{n}=7)^{435660-64}$ and liraglutide versus lixisenatide $(\mathrm{n}=5) .{ }^{23} 4365-67$

Economic studies were mainly performed using a payer's perspective, except for 10 comparisons $\left(n=7^{27364145535864}\right)$ that used a societal perspective (online supplementary table 1). The mean age of patients ranged from 50.9 to 64.7 years. Comparisons used models based on lifetime $(n=27)$ or non-lifetime horizons $(n=53)$; two had no time horizon information $(n=2)$. Comparisons were mainly from HIC; only eight comparisons $\left(n=7^{2853-55576264}\right)$ were from UMIC and none from LMIC/LIC. For the sources of model input parameters, the majority of comparisons $(n=41)$ used single study-based estimates, followed by multiple study-based $(n=28)$, synthesis-based $(n=12)$ and hospital-based. ${ }^{64}$ The gross domestic product (GDP)-based thresholds were used for WTP in 12 comparisons $\left(\mathrm{n}=8^{28} 36464853-5568\right)$, and nine comparisons $\left(n=5^{21} 26315264\right)$ did not mention/unclear, and the rest used country-specific thresholds (online supplementary table 2). Sensitivity analysis was performed using PSA in all except 13 studies. $^{20} 212426283031354349515256$

Four comparisons $(n=3)$ reported that GLP1s were not cost-effective compared with insulin, ${ }^{51}$ sulfonylureas, ${ }^{26}$ DPP4i, ${ }^{26}$ and SGLT2 plus sulfonylureas ${ }^{69}$; four comparisons from a single study ${ }^{30}$ did not compare with any threshold; and the rest of GLP1 comparisons were costeffective or superior relative to comparators (see online supplementary table 1).

Risk of bias assessment was performed (online supplementary figure 1). Most studies had a similar bias profile, except double counting and reporting/ 


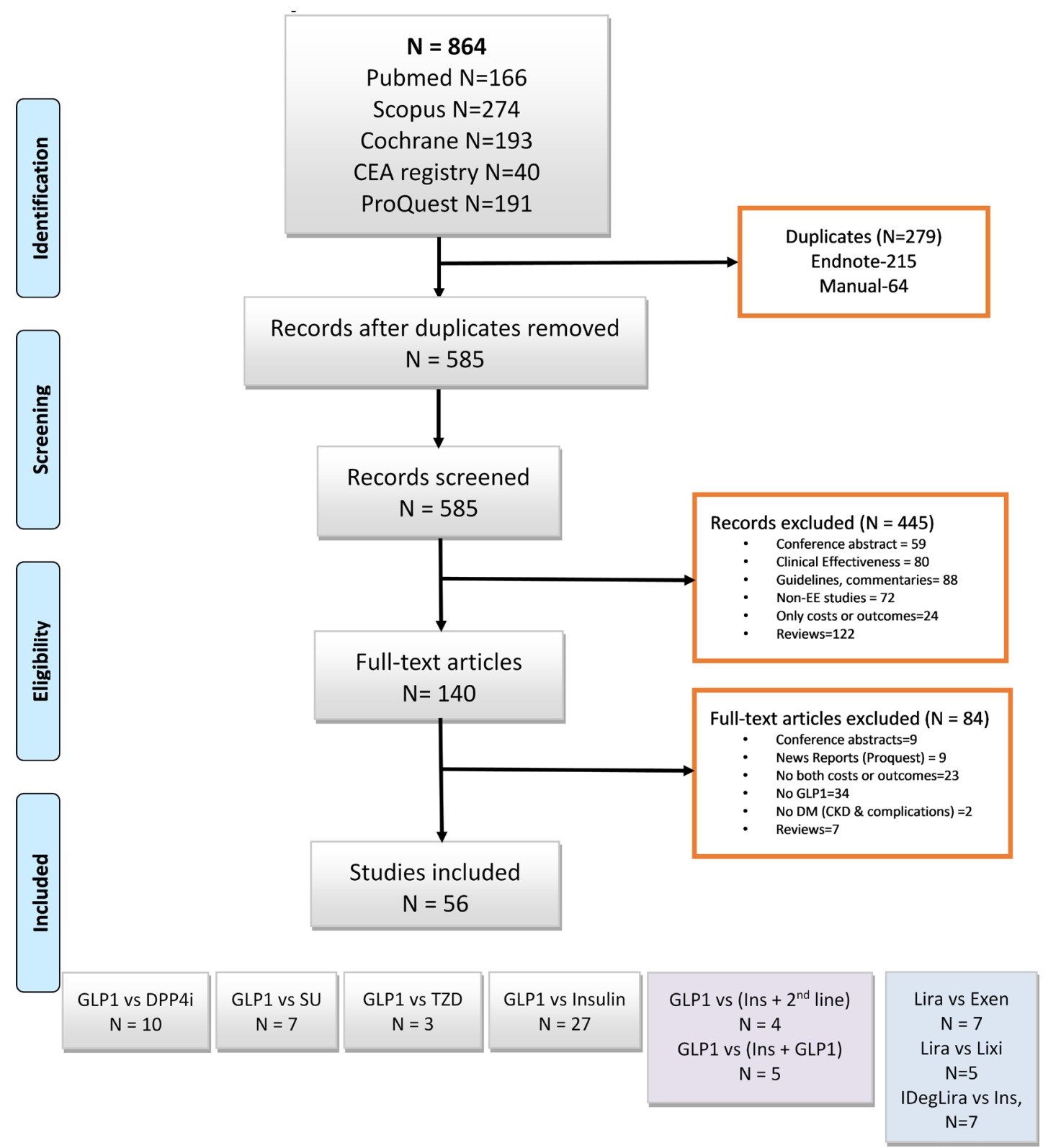

Figure 1 Study selection flow of GLP1 pooling. CEA, Cost-Effectiveness Analysis; CKD, chronic kidney disease; DM, diabetes mellitus; DPP4i, dipeptidyl peptidase-4 inhibitor; Exen, exenatide; EE, economic evaluation; GLP1, glucagon-like peptide 1; IDegLira, insulin degludec/liraglutide; Lira, liraglutide; Lixi, lixisenatide; SU, Sulfonylurea; TZD, thiazolidinedione.

dissemination had unclear information. Four 35515257 and 14 studies 2124283035364951525457616669 had bias related to model structures and data, respectively. All studies were unclear for internal consistency bias.

\section{GLP1 versus DPP4i}

INBs of GLP1 versus DPP4i were estimated $\left(n=10^{18-27}\right)$, and all were from HICs with no heterogeneity $\left(\mathrm{I}^{2}=0\right.$, figure $2 \mathrm{~A})$. The INB was US $\$ 4012.21$ (95\% CI US $\$-571.43$ to US\$8595.84), which favours GLP1 compared with DPP4i, but does not reach statistical significance.

The threshold used for these comparisons ranged from US\$29 382 to US\$58 024. A sensitivity analysis omitting the study that used a societal perspective ${ }^{27}$ and the study that did not use discounting ${ }^{19}$ yielded INB $_{\mathrm{p}} \mathrm{s}$ of US $\$ 4032.07$ $\left(95 \%\right.$ CI US $\$-554.48$ to US\$8618.61) ${ }^{\mathrm{p}}$ and US $\$ 4068.19$
(95\% CI US\$-650.66 to US\$8787.04), respectively (online supplementary figure 2A,B). These estimates are very similar to the main result and are robust.

In addition, subgroup analyses by WTP threshold (< vs $\geq$ median of US $\$ 49325$ ), time horizon, and source of effectiveness measure were performed, indicating GLP1s were not significantly cost-effective compared with DPP4i in any subgroup (online supplementary figure 3A-C). There was no evidence of publication bias in either a funnel plot (online supplementary figure 4) or Egger's test (coefficient $=0.32, \mathrm{SE}=0.73, \mathrm{p}=0.672$ ).

\section{GLP1 versus sulfonylureas}

Seven studies ${ }^{25-3034}$ compared GLP1 versus sulfonylureas, and all were conducted in HICs except one study. ${ }^{28}$ INBs of HIC were moderately heterogeneous $\left(\mathrm{I}^{2}=45.9\right.$; 


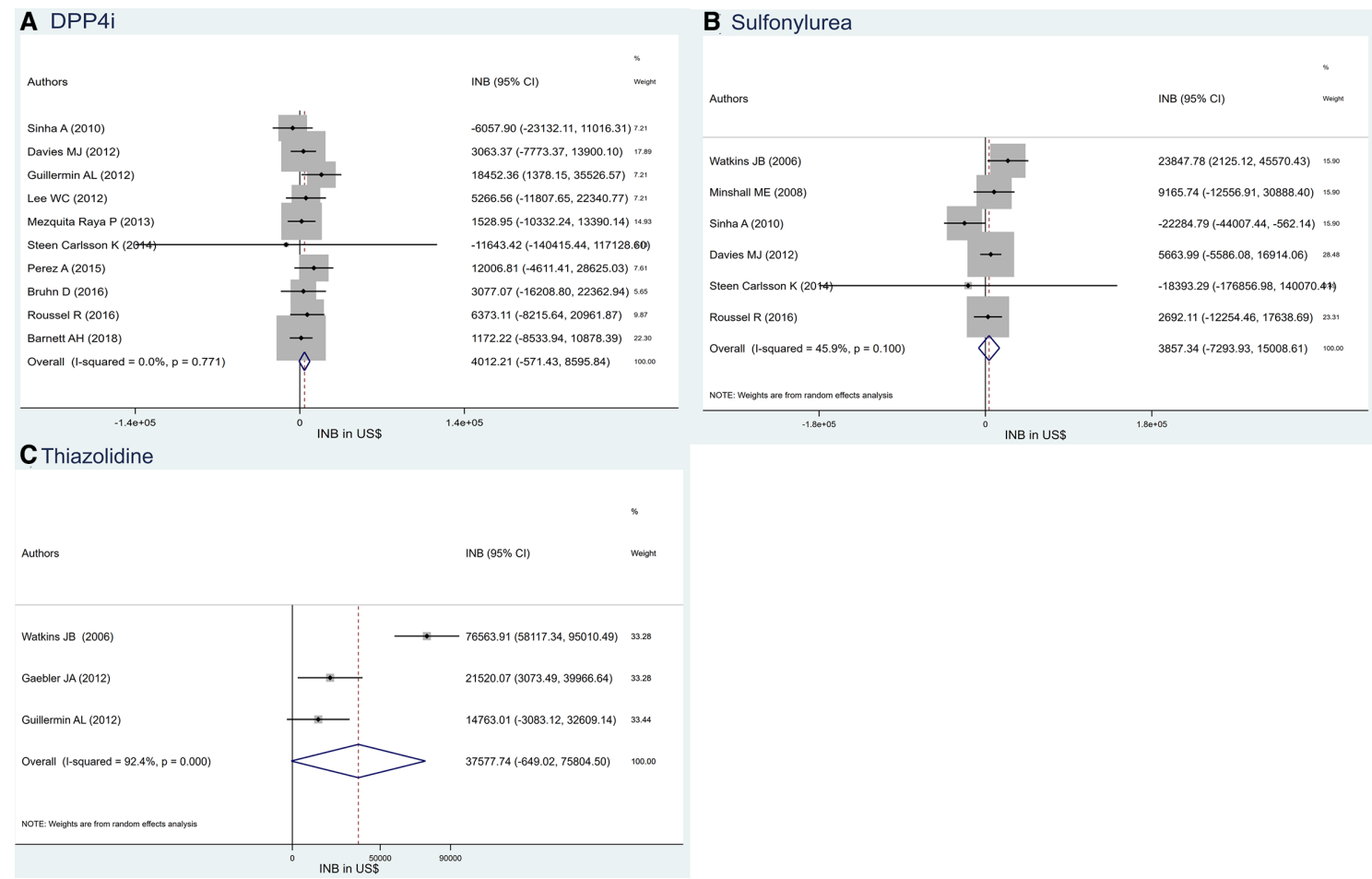

Figure 2 Pooling INB of glucagon-like peptide 1 versus (A) DPP4i, (B) sulfonylurea and (C) thiazolidines and its funnel plot. DPP4i, dipeptidyl peptidase-4 inhibitor; INB, incremental net benefit.

see figure 2B) with an $\mathrm{INB}_{\mathrm{p}}$ of US\$3857.34 (95\% CO US\$-7293.93 to US\$15 008.61), that is, again favouring GLP1 compared with sulfonylureas but not reaching statistical significance.

The threshold used varied from US $\$ 34905$ to US $\$ 62757$. Omitting two studies with the highest WTP threshold, ${ }^{29} 30$ societal perspective, ${ }^{27}$ or no discounting ${ }^{30}$ from overall pooling yielded INB $\mathrm{s}$ of US\$-1775.65 (95\% CI US\$-14 537.27 to 10985.97 ), US $\$ 3947.85$ (95\% CI US $\$-7865.66$ to US $\$ 15761.36)$ and US $\$ 606.93$ (95\% CI -9647.87 to US\$10 861.72), respectively (see online supplementary figure $5 \mathrm{~A}-\mathrm{C}$ ). These $\mathrm{INB}_{\mathrm{p}} \mathrm{s}$ were not significant; that is, GLP1 was not cost-effective compared with sulfonylureas. Subgroup analyses showed that GLP1s were cost-effective compared with sulfonylureas at thresholds $\geq$ US $\$ 57474$ and with a non-life-time horizon (see online supplementary figure $6 \mathrm{~A}-\mathrm{C}$ ). No evidence of publication bias was suggested by either a funnel plot (see online supplementary figure 7) or Egger's test (coefficient $=-0.32, \mathrm{SE}=1.38$, $\mathrm{p}=0.825)$.

\section{GLP1 versus thiazolidines}

INBs of GLP1s versus thiazolidines from $\mathrm{HICs}^{21} 3031$ showed high heterogeneity $\left(\mathrm{I}^{2}=92.4\right.$; see figure $\left.2 \mathrm{C}\right)$. The $\mathrm{INB}_{\mathrm{p}}$ was US $\$ 37577.74$ (95\% CI US $\$-649.02$ to US $\$ 75$ 804.50), that is, again favouring GLP1 compared with thiazolidines but not reaching significance. There was some asymmetry in the funnel plot (see online supplementary figure 8 ), but with the small number of included studies, this was not reliable.

\section{GLP1 versus insulins}

Among the studies looking at GLP1s versus insulins, 24 and $3^{53-55}$ were from HICs and UMICs. One study ${ }^{51}$ had an outlier INB (based on scenario 5) and was excluded. The INBs were highly heterogeneous $\left(I^{2}=86.4\right)$ with a pooled $\mathrm{INB}_{\mathrm{p}}$ of US $\$ 14062.42$ (95\% CI US $\$ 8168.69$ to US $\$ 19$ 956.15) (see online supplementary figure 9A); that is, GLP1s were cost-effective compared with insulins in HICs.

The thresholds ranged from US\$6411 to 103418. Omitting studies with the highest ${ }^{70}$ and lowest WTP threshold,${ }^{33}$ those without discounting, ${ }^{303135}$ and those using a societal perspective ${ }^{364145}$ from overall pooling resulted in INB s of US $\$ 14136.28$ (95\% CI US $\$ 8163.24$ to US\$20 109.32), US\$14 954.40 (95\% CI US $\$ 8434.54$ to US\$21 474.26), US\$13 214.95 (US\$6905.07 to US\$19 524.82 ), and US $\$ 12889.17$ (95\% CI US $\$ 7073.30$ to US $\$ 18$ 705.05), respectively (see online supplementary figure $10 \mathrm{~A}-\mathrm{D})$. The $\mathrm{INB}_{\mathrm{p}} \mathrm{s}$ were robust for all conditions; that is, GLP1s were cost-effective compared with insulins in all sensitivity analyses. Subgroup analyses by median WTP threshold (US\$52 359), time horizon, and source of effectiveness measure indicated GLP1s were significantly cost-effective in all subgroups (see online supplementary figure $11 \mathrm{~A}-\mathrm{C}$ ). Funnel plots (online supplementary figure 12A) and Egger's test (coefficient $=1.76, \mathrm{SE}=0.73$, $\mathrm{p}=0.025$ ) showed asymmetry. A contour-enhanced funnel plot was constructed (online supplementary figure 12B), suggesting that asymmetry may be due to both heterogeneity and missing studies in significant areas.

GLP1s were not cost-effective compared with insulins

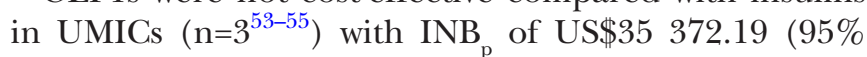


A Lira vs. Exen

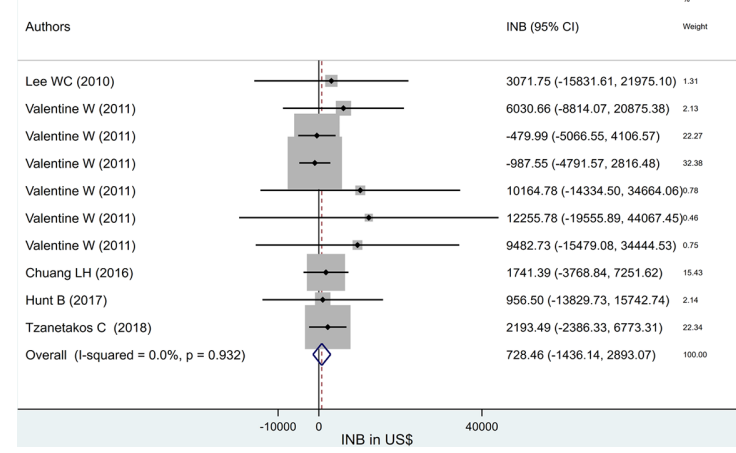

B Lira vs. Lixi

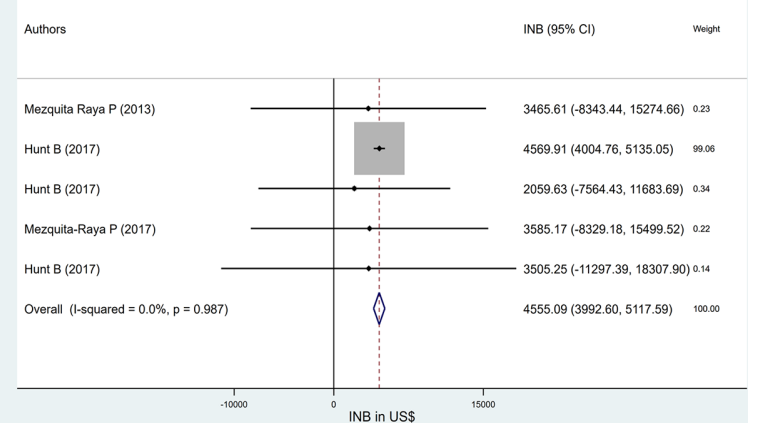

Figure 3 Pooling INB of Lira versus (A) Exen and (B) Lixi. Exen, exenatide; INB, incremental net benefit; Lira, liraglutide; Lixi, lixisenatide.

CI US $\$-9955.53$ to US $\$ 80899.91, \mathrm{I}^{2}=91.3 \%$ ), see online supplementary figure 9B. A funnel plot and Egger's test (coefficient $=3.40, \mathrm{SE}=0.07, \mathrm{p}=0.013$ ) showed asymmetry; a contour-enhanced funnel plot suggested that this may be due to both heterogeneity and missing studies (see online supplementary figure 13A,B).

\section{Liraglutide versus exenatide}

Among 12 comparisons ( $\mathrm{n}=7^{43} 56^{60-64}$ ) of liraglutide versus exenatide, 10 comparisons $(n=5)$ from HICs were pooled with no heterogeneity $\left(\mathrm{I}^{2}=0\right)$. The $\mathrm{INB}_{\mathrm{p}}$ was US $\$ 728.46$ (95\% CI US $\$-1436.14$ to US $\$ 2893.07$ ) (see figure 3A); that is, liraglutide was not more costeffective compared with exenatide. Omitting studies with exenatide plus sulfonylureas, ${ }^{61}{ }^{62}$ or highest and lowest WTP threshold ${ }^{63}$ from overall pooling, yielded INB $\mathrm{s}$ of US $\$ 697.33$ (95\% CI US $\$-1481.61$ to US $\$ 2876.27)^{\mathrm{p}}$, US\$674.84 (95\% CI US\$-1494.79 to US\$2844.48) and US\$1550.17 (95\% CI US\$-1082.16 to US $\$ 4182.50$ ), respectively (see online supplementary figure $14 \mathrm{~A}-\mathrm{C}$ ), indicating that liraglutide was not more cost-effective compared with exenatide.

Liraglutide was not more cost-effective in subgroups of WTP threshold (median US\$50 967) or source of effectiveness (see online supplementary figure 15A,B). A funnel plot (see online supplementary figure 16A) and Egger's test (coefficient $=0.78, \mathrm{SE}=0.24, \mathrm{p}=0.01$ ) suggested asymmetry; a contour-enhanced funnel plot further suggested that this may be due to missing studies in significant areas (see online supplementary figure 16B).

\section{Liraglutide versus lixisenatide}

INBs of liraglutide versus lixisenatide were estimated in $\mathrm{HICs}^{23} 4365-67$ with no heterogeneity $\left(\mathrm{I}^{2}=0\right)$. The $\mathrm{INB}_{\mathrm{p}}$ was US $\$ 4555.09$ (95\% CI US\$3992.60 to US\$5117.59); that is, liraglutide was significantly more cost-effective compared with lixisenatide (see figure 3B).

Omitting highest and lowest WTP thresholds ${ }^{43}$ yielded $\mathrm{INB}_{\mathrm{p}} \mathrm{s}$ of US $\$ 4556.61$ (95\% CI US $\$ 3993.71$ to US $\$ 5119.51)^{\mathrm{P}}$ and US\$4563.65 (95\% CI US $\$ 4000.19$ to US\$5127.11), respectively (see online supplementary figure $17 \mathrm{~A}, \mathrm{~B})$; that is, the $\mathrm{INB}_{\mathrm{p}} \mathrm{s}$ were robust. There was no evidence of publication bias by either funnel plot (online supplementary figure 18) or Egger's test (coefficient $=-0.26, \mathrm{SE}=0.09, \mathrm{p}=0.069$ ).

\section{GLP1s versus insulin plus second-line drugs}

INBs of GLP1s versus insulin plus other second-line agents (ie, insulin plus DPP $4 \mathrm{i}^{45} 56$ and insulin plus sulfonylureas ${ }^{52}$ ) from HICs were pooled $\left(\mathrm{I}^{2}=0\right)$ with $\mathrm{INB}_{\mathrm{p}}$ of US $\$ 2071.10$ (95\% CI US $\$-10355.78$ to US $\$ 14$ 497.99, online supplementary figure 19A), indicating that GLP1 was not cost-effective compared with insulin plus other second-line agents. There was no evidence of publication bias on Egger's test (coefficient $=-1.75$, $\mathrm{SE}=0.53, \mathrm{p}=0.189$ ).

The INB of GLP1s versus insulin plus GLPs from four $\mathrm{HICs}^{36} 4246^{\mathrm{P}} 5558$ was US\$20 509.08 (95\% CI US\$5435.21 to US\$35 582.94, online supplementary figure 19B), indicating GLP1s were significantly more cost-effective compared with insulin plus GLP1s.

Omitting the studies with the highest WTP threshold and with a lifetime horizon ${ }^{46}$ resulted in INB of US\$19 913.92 (95\% CI US $\$-2496.45$ to US $\$ 42324.29$ ) and US\$26 396.17 (95\% CI US $\$ 9067.27$ to US $\$ 43725.07$ ), respectively (see online supplementary figure 20A,B). GLP1s were no longer cost-effective compared with insulin plus GLP1s after omitting the highest threshold study. There was no evidence of publication bias on funnel plot (online supplementary figure 21) or Egger's test (coefficient $=-1.49, \mathrm{SE}=4.57, \mathrm{p}=0.775)$.

\section{IDegLira versus insulin}

INBs of IDegLira versus insulin from HICs ${ }^{34-36} 42464859$ showed high heterogeneity $\left(\mathrm{I}^{2}=87.6\right)$. The $\mathrm{INB}_{\mathrm{p}}$ was US $\$ 15649.28$ (95\% CI US $\$ 3748.17$ to US $\$ 27550.39$ ); that is, IDegLira was more cost-effective compared with insulin (see online supplementary figure 19C).

Omitting the highest ${ }^{70}$ and lowest WTP thresholds ${ }^{59}$ studies and the one using a societal perspective ${ }^{36}$ from overall pooling resulted in INB $\mathrm{s}$ of US $\$ 16078.96$ (95\% CI US $\$ 3537.45$ to US $\$ 28620.46$ ), $\$ 15440.64$ (95\% CI US\$2091.91 to US\$28 789.38), and US\$5164.81 (95\% CI US $\$ 1129.32$ to US $\$ 9200.30$ ), respectively (see online supplementary figure $22 \mathrm{~A}-\mathrm{C}$ ). The $\mathrm{INB}_{\mathrm{p}} \mathrm{s}$ were robust; that is, IDegLira was still cost-effective. In addition, 


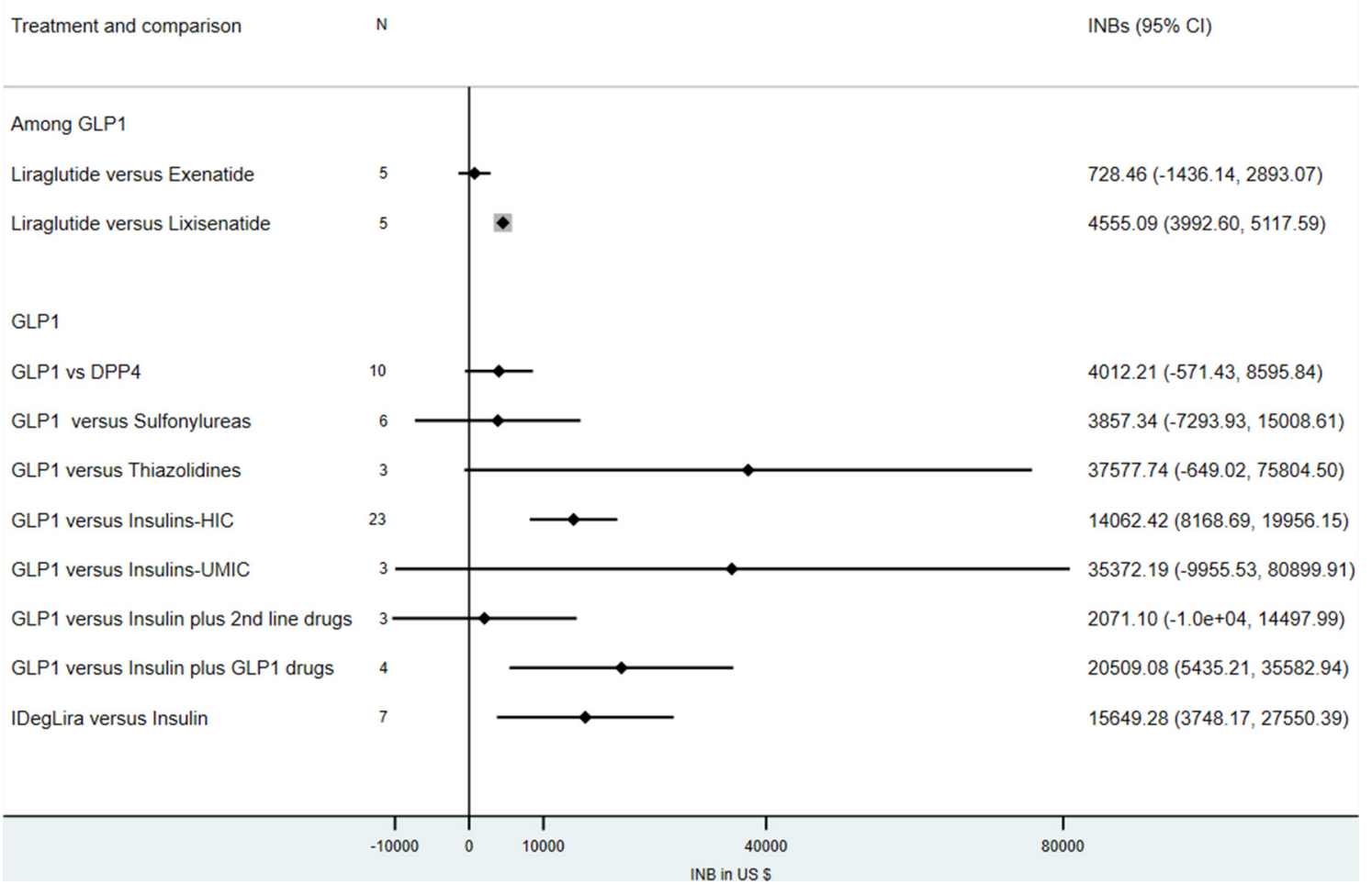

Figure 4 INB summary of GLP1 comparisons. GLP1, glucagon-like peptide 1; HIC, high-income countries; IDegLira, insulin degludec/liraglutide; INB, incremental net benefit; UMIC, upper-income to middle-income countries.

IDegLira was still cost-effective in subgroups based on time horizon and source of effectiveness, but not in WTP<US\$42 049 (see online supplementary figure $23 \mathrm{~A}-\mathrm{C})$. There was no evidence of publication bias in the funnel plot (online supplementary figure 24) or Egger's test (coefficient $=2.79, \mathrm{SE}=1.86, \mathrm{p}=0.194$ ).

\section{DISCUSSION}

Meta-analysis of economic studies suggests that GLP1s are significantly more cost-effective compared with insulin in HICs but not in UMICs (figure 4); point estimates versus other antidiabetic agents, including DPP4i, sulfonylureas, and thiazolidines, also favour GLP-1, but these did not reach statistical significance. In addition, GLP1s are significantly cost-effective compared with insulin plus GLP1s, but not for insulin plus other secondline drugs. Furthermore, among GLP1 agonists, liraglutide was significantly more cost-effective compared with lixisenatide but not exenatide. Lastly, IDegLira was also significantly more cost-effective compared with insulin.

The GLP1s were cost-effective compared with insulins, mainly in HICs but not in UMICs. Although results had highly heterogeneity, they were very robust across multiple sensitivity and subgroup analyses, although there was some indication of publication bias. GLP1s were not cost-effective compared with insulin in UMICs, but this was based on only three studies.

The GLP1s were not cost-effective compared with DPP4i, sulfonylureas, and thiazolidines with varying degrees of heterogeneity $(0 \%-92.7 \%)$. Interestingly,
GLP1s were cost-effective in a subgroup analysis of sulfonylureas with respect to time horizon (lifetime vs nonlifetime), indicating that GLP1s would be cost-effective in the short term rather than the long term. In other words, DPP4i, sulfonylureas, and thiazolidines could be the drug of choice in the long term, but GLP1s might be a better choice in the short-term.

Results also suggested that treatment with GLP1s alone was significantly more cost-effective than insulin plus GLP1s, but not when compared with insulin plus secondline agents. This suggests that the combination of GLP1 with insulin might not be a good choice, but combining insulin with another second-line drug (eg, DPP4i and sulfonylureas) might be beneficial. This is consistent with our finding that IDegLira, a fixed-dose combination of insulin and degludec/liraglutide, was cost-effective compared with only insulin therapy.

Most findings of these economic studies relied on the point estimate ICER (ie, deterministic ICER) for decision making while ignoring the measures of dispersion. This meta-analysis considered ranges of ICERs rather than the point estimates. This study standardized monetary units by converting them to 2017 \$US using the Consumer Price Index (CPI) and PPP conversions, which provided reliability of cost-effectiveness for the most recent time point considering a country's economic changes across time. In addition, PPP adjustment provides values for comparison across the globe, even when considering different worldwide economic conditions and time-lag adjustments. 
Although many previous reviews of economic evaluations of T2DM treatments have been performed, ${ }^{71-77}$ these were narrative reviews, ${ }^{72} 73$ or systematic reviews ${ }^{7172747879}$ without synthesis of economic outcomes, or focused on cost/burden of illness. ${ }^{73-76}$ Our study reported pooled economic results that were adjusted with PPP and time-lag and standardized across countries.

\section{Strengths and limitations}

Our study had significant strengths. Given that economic evaluation studies varied in reporting results, we calculated and pooled a common economic parameter using meta-analysis stratified by country income, which has rarely been performed before. Five scenarios were constructed to calculate this common parameter and standardize it before pooling. The different monetary units were all converted to a common standard currency. We used INB instead of ICER as the economic effect measure because of limitations of the ICER. ${ }^{80}$ For instance, a negative ICER may indicate a lower cost compared with higher effectiveness of intervention or higher cost, along with lower effectiveness of intervention, thus introducing ambiguity in interpretation ${ }^{16}{ }^{81}$; in contrast, positive and negative INBs directly indicate cost-effectiveness and non-cost-effectiveness, which is the information required by policy makers. ${ }^{82} 83$ Such information helps provide evidence informed policy for decision makers from both resource-rich and resourcepoor countries.

Another challenge for pooling economic studies was heterogeneity, caused by study design (model or alongside clinical trials), population, country, GDP, or economic perspective taken. The CPI and PPP were applied to standardize different economic backgrounds, as well as the time lag across the studies. ${ }^{84} 85$ However, it should be noted that using PPP may have some limitation related to the method of parity estimation as price indices are calculated from individual prices of only selected commodities rather than all commodities in each country. ${ }^{86}$ In addition, results from economic studies depend greatly on important factors such as WTP thresholds, analytical time horizons, country income or GDP, effectiveness measurement used, discount rates, and perspectives. These factors were taken into account by performing stratified analyses by level of country income, subgroup analyses, and sensitivity analyses where appropriate.

Our study also has some limitations. These findings apply largely to HICs. Although we used five scenarios to estimate variances of the outcome measure (ie, ICER), we could not assess validity of data, particularly for scenarios 3-4 from Monte Carlo simulation or extraction of data from the CE plane by WebPlotDigitizer due to lack of actual or raw data obtained from these studies. In addition, it should be noted that individual countries differ in T2DM prevalence, patient behaviors, treatment regimens and accessibility, and healthcare systems. Therefore, all these factors should be considered when applying our findings.

Future primary studies may be directed towards bridging the current knowledge gap in terms of studies from LIC and LMIC economies, inclusion of other antidiabetic drug groups for comparison, as well as by following a standard reporting format for economic studies, that is, reporting the measures of dispersion of the study point estimates and reporting the INB rather than just ICER. In terms of meta-analysis, further finetuning and standardization of meta-analysis of economic evaluation study methods is essential mainly in terms of standardization of data-extraction methods/guidelines in economic studies, and assessment of heterogeneity and publication. In addition, future studies may explore the feasibility of conducting a network metaanalysis of economic studies.

\section{CONCLUSION}

In HICs, GLP1s and IDegLira appear to be more costeffective than insulins, but not DPP4i, sulfonylureas, and thiazolidines. Liraglutide appears to be more cost-effective compared with lixisenatide but not exenatide. Further primary economic evaluation studies in LICs and UMICs are required to address gaps in the literature.

\section{Author affiliations}

${ }^{1}$ Non-Communicable Diseases, ICMR-National Institute of Epidemiology, Chennai, India

${ }^{2}$ Mahidol University Health Technology Assessment (MUHTA) Graduate Program, Mahidol University, Bangkok, Thailand

${ }^{3}$ Social and Administrative Pharmacy Division, Department of Pharmacy, Faculty of Pharmacy, Mahidol University, Bangkok, Thailand

${ }^{4}$ Epidemiology Group, ICMR-National Institute of Virology, Pune, India

${ }^{5}$ Department of Family Medicine, Faculty of Medicine Ramathibodi Hospital, Mahidol University, Bangkok, Thailand

${ }^{6}$ College of Pharmacy, University of Utah, Salt Lake City, Utah, USA

${ }^{7}$ Centre for Clinical Epidemiology and Biostatistics, Hunter Medical Research Institute, School of Medicine and Public Health, University of Newcastle, New Lambton, New South Wales, Australia

${ }^{8}$ Division of Medicine, John Hunter Hospital, New Lambton, New South Wales, Australia

${ }^{9}$ Department of Clinical Epidemiology and Biostatistics, Faculty of Medicine Ramathibodi Hospital, Mahidol University, Bangkok, Thailand

Acknowledgements BSB and YKG acknowledged the financial support through a fellowship by the department of health research, government of India under Human Resource Development program, Indian Council of Medical Research. This article is an important part of the training of BSB, who is a master's student in health technology assessment at Mahidol University, Bangkok, Thailand.

Contributors BSB performed data extraction, meta-analysis, data interpretation and wrote the manuscript. UC designed and supervised meta-analysis, checked data accuracy, and assisted in writing and revising the manuscript. YKG performed data extraction and meta-analysis and wrote the manuscript. TA and SY assisted in supervising the meta-analysis and writing the manuscript. MMcE, NC, and JA contributed to data interpretation, as well as writing and revising the manuscript. AT designed and supervised meta-analysis, checked data accuracy and assisted in writing and revising the manuscript. All authors reviewed and approved the revised manuscript.

Funding This work is a part of training in Health Technology Assessment's master's degree, in which scholarship is provided by Mahidol University and the International Decision Support Initiative (iDSI). This work was produced as part of 
the International Decision Support Initiative (www.idsihealth.org), which supports countries to get the best value for money from health spending. iDSI receives funding support from the Bill and Melinda Gates Foundation, the UK Department for International Development, and the Rockefeller Foundation.

Disclaimer The findings, interpretations and conclusions expressed in this article do not necessarily reflect the views of the aforementioned funding agencies.

\section{Competing interests None declared.}

Patient consent for publication Not required.

Provenance and peer review Not commissioned; externally peer reviewed.

Data availlability statement All data relevant to the study are included in the article or uploaded as supplementary information. All the primary data were collected from published journals and reported in the manuscript.

Open access This is an open access article distributed in accordance with the Creative Commons Attribution 4.0 Unported (CC BY 4.0) license, which permits others to copy, redistribute, remix, transform and build upon this work for any purpose, provided the original work is properly cited, a link to the licence is given, and indication of whether changes were made. See: https://creativecommons.org/ licenses/by/4.0/.

ORCID iDs

Bhavani Shankara Bagepally http://orcid.org/0000-0003-0856-767X

Usa Chaikledkaew http://orcid.org/0000-0001-9457-9823

\section{REFERENCES}

1 Hesselbjerg LJ, Pedersen HS, Asmussen MB, et al. Is dabigatran considered a cost-effective alternative to warfarin treatment: a review of current economic evaluations worldwide. J Med Econ 2013;16:845-58

2 Anjana RM, Deepa M, Pradeepa R, et al. Prevalence of diabetes and prediabetes in 15 states of India: results from the ICMR-INDIAB population-based cross-sectional study. Lancet Diabetes Endocrinol 2017:5:585-96.

3 DeFronzo RA, Abdul-Ghani MA. Preservation of $\beta$-cell function: the key to diabetes prevention. J Clin Endocrinol Metab 2011;96:2354-66.

4 Wang L-G, Wang H, Liu Q, et al. A network meta-analysis for efficacy and safety of seven regimens in the treatment of type II diabetes. Biomed Pharmacother 2017;92:707-19.

5 American Diabetes Association. 8. Pharmacologic Approaches to Glycemic Treatment: Standards of Medical Care in Diabetes-2018. Diabetes Care 2018;41:S73-85.

6 Fei Y, Tsoi M-F, Kumana CR, et al. Network meta-analysis of cardiovascular outcomes in randomized controlled trials of new antidiabetic drugs. Int J Cardiol 2018;254:291-6.

7 Zhong X, Zhang T, Liu Y, et al. Effects of three injectable antidiabetic agents on glycaemic control, weight change and drop-out in type 2 diabetes suboptimally controlled with metformin and/or a sulfonylurea: a network meta-analysis. Diabetes Res Clin Pract 2015;109:451-60.

8 Garber AJ, Abrahamson MJ, Barzilay JI, et al. Consensus Statement by the American Association of Clinical Endocrinologists and American College of Endocrinology on the Comprehensive Type 2 Diabetes Management Algorithm - 2018 Executive Summary. Endocr Pract 2018;24:91-120.

9 Bagepally BS, Gurav YK, Anothaisintawee T, et al. Cost utility of sodium-glucose cotransporter 2 inhibitors in the treatment of metformin monotherapy failed type 2 diabetes patients: a systematic review and meta-analysis. Value Health 2019;22:1458-69.

10 Haider S, Chaikledkaew U, Thavorncharoensap M, et al. Systematic review and meta-analysis of cost-effectiveness of rotavirus vaccine in low-income and Lower-Middle-Income countries. Open Forum Infect Dis 2019;6:ofz117.

11 Shamseer L, Moher D, Clarke M, et al. Preferred reporting items for systematic review and meta-analysis protocols (PRISMA-P) 2015: elaboration and explanation. BMJ 2015;350:g7647.

12 Rattanachotphanit T, Limwattananon C, Waleekhachonloet O, et al. Cost-Effectiveness analysis of direct-acting oral anticoagulants for stroke prevention in Thai patients with Non-Valvular atrial fibrillation and a high risk of bleeding. Pharmacoeconomics 2019;37:279-89.

13 Adarkwah CC, van Gils PF, Hiligsmann M, et al. Risk of bias in model-based economic evaluations: the ECOBIAS checklist. Expert Rev Pharmacoecon Outcomes Res 2016;16:513-23.
14 Stinnett AA, Mullahy J. Net health benefits: a new framework for the analysis of uncertainty in cost-effectiveness analysis. Med Decis Making 1998;18:S68-80.

15 Shah SJ, Eckman MH, Aspberg S, et al. Effect of variation in published stroke rates on the net clinical benefit of anticoagulation for atrial fibrillation. Ann Intern Med 2018;169:517-27.

16 Crespo C, Monleon A, Díaz W, et al. Comparative efficiency research (COMER): meta-analysis of cost-effectiveness studies. BMC Med Res Methodol 2014;14:139.

17 Khan MS, Ali I, Tahir F, et al. Simultaneous analysis of the three hormones involved in spermatogenesis and their interrelation ratios. Pak J Pharm Sci 2008;21:344-9.

18 Barnett $\mathrm{AH}$, Arnoldini S, Hunt B, et al. Switching from sitagliptin to liraglutide to manage patients with type 2 diabetes in the UK: a long-term cost-effectiveness analysis. Diabetes Obes Metab 2018;20:1921-7

19 Bruhn D, Martin AA, Tavares R, et al. Cost-utility of albiglutide versus insulin lispro, insulin Glargine, and sitagliptin for the treatment of type 2 diabetes in the US. J Med Econ 2016;19:672-83.

20 Davies MJ, Chubb BD, Smith IC, et al. Cost-utility analysis of liraglutide compared with sulphonylurea or sitagliptin, all as add-on to metformin monotherapy in type 2 diabetes mellitus. Diabet Med 2012;29:313-20.

21 Guillermin A-L, Lloyd A, Best JH, et al. Long-term cost-consequence analysis of exenatide once Weekly vs sitagliptin or pioglitazone for the treatment of type 2 diabetes patients in the United States. J Med Econ 2012;15:654-63.

22 Lee WC, Samyshkin Y, Langer J, et al. Long-term clinical and economic outcomes associated with liraglutide versus sitagliptin therapy when added to metformin in the treatment of type 2 diabetes: a core diabetes model analysis. J Med Econ 2012;15(Suppl 2):28-37.

23 Mezquita Raya P, Pérez A, Ramírez de Arellano A, et al. Incretin therapy for type 2 diabetes in Spain: a cost-effectiveness analysis of liraglutide versus sitagliptin. Diabetes Ther 2013;4:417-30.

24 Pérez A, Mezquita Raya P, Ramírez de Arellano A, et al. Costeffectiveness analysis of incretin therapy for type 2 diabetes in Spain: $1.8 \mathrm{mg}$ liraglutide versus sitagliptin. Diabetes Ther 2015;6:61-74.

25 Roussel R, Martinez L, Vandebrouck T, et al. Evaluation of the longterm cost-effectiveness of liraglutide therapy for patients with type 2 diabetes in France. J Med Econ 2016;19:131-44.

26 Sinha A, Rajan M, Hoerger T, et al. Costs and consequences associated with newer medications for glycemic control in type 2 diabetes. Diabetes Care 2010;33:695-700.

27 Steen Carlsson K, Persson U. Cost-effectiveness of add-on treatments to metformin in a Swedish setting: liraglutide vs sulphonylurea or sitagplitin. J Med Econ 2014;17:658-69.

28 Gao L, Zhao F-L, Li S-C. Cost-utility analysis of liraglutide versus glimepiride as add-on to metformin in type 2 diabetes patients in China. Int J Technol Assess Health Care 2012;28:436-44.

29 Minshall ME, Oglesby AK, Wintle ME, et al. Estimating the long-term cost-effectiveness of exenatide in the United States: an adjunctive treatment for type 2 diabetes mellitus. Value Health 2008;11:22-33.

30 Watkins JB, Minshall ME, Sullivan SD. Application of economic analyses in U.S. managed care formulary decisions: a private payer's experience. J Manag Care Pharm 2006;12:726-35.

31 Gaebler JA, Soto-Campos G, Alperin P, et al. Health and economic outcomes for exenatide once Weekly, insulin, and pioglitazone therapies in the treatment of type 2 diabetes: a simulation analysis. Vasc Health Risk Manag 2012;8:255-64.

32 Beaudet A, Palmer JL, Timlin L, et al. Cost-utility of exenatide once Weekly compared with insulin Glargine in patients with type 2 diabetes in the UK. J Med Econ 2011;14:357-66.

33 Brändle M, Erny-Albrecht KM, Goodall G, et al. Exenatide versus insulin Glargine: a cost-effectiveness evaluation in patients with type 2 diabetes in Switzerland. Int J Clin Pharmacol Ther 2009;47:501-15.

34 Davies MJ, Glah D, Chubb B, et al. Cost effectiveness of IDegLira vs. alternative basal insulin intensification therapies in patients with type 2 diabetes mellitus uncontrolled on basal insulin in a UK setting. Pharmacoeconomics 2016;34:953-66.

35 Drummond R, Malkin S, Du Preez M, et al. The management of type 2 diabetes with fixed-ratio combination insulin degludec/liraglutide (IDegLira) versus basal-bolus therapy (insulin Glargine U100 plus insulin aspart): a short-term cost-effectiveness analysis in the UK setting. Diabetes Obes Metab 2018;20:2371-8.

36 Ericsson Åsa, Lundqvist A. Cost effectiveness of insulin degludec plus liraglutide (IDegLira) in a fixed combination for uncontrolled type 2 diabetes mellitus in Sweden. Appl Health Econ Health Policy 2017:15:237-48. 
37 Fonseca T, Clegg J, Caputo G, et al. The cost-effectiveness of exenatide once weekly compared with exenatide twice daily and insulin glargine for the treatment of patients with type two diabetes and body mass index $\geq 30 \mathrm{~kg} / \mathrm{m}(2)$ in Spain. $J$ Med Econ 2013;16:926-38

38 Goodall G, Costi M, Timlin L, et al. [Cost-effectiveness of exenatide versus insulin glargine in Spanish patients with obesity and type 2 diabetes mellitus]. Endocrinol Nutr 2011;58:331-40.

39 Gordon J, McEwan P, Sabale U, et al. The cost-effectiveness of exenatide twice daily (BID) vs insulin lispro three times daily (TID) as add-on therapy to titrated insulin Glargine in patients with type 2 diabetes. J Med Econ 2016;19:1167-74.

40 Gourzoulidis G, Tzanetakos C, loannidis I, et al. Cost-effectiveness of Empagliflozin for the treatment of patients with type 2 diabetes mellitus at increased cardiovascular risk in Greece. Clin Drug Investig 2018;38:417-26.

41 Huetson P, Palmer JL, Levorsen A, et al. Cost-effectiveness of once daily GLP-1 receptor agonist lixisenatide compared to bolus insulin both in combination with basal insulin for the treatment of patients with type 2 diabetes in Norway. $J$ Med Econ 2015;18:573-85.

42 Hunt B, Mocarski M, Valentine WJ, et al. Evaluation of the long-term cost-effectiveness of IDegLira versus liraglutide added to basal insulin for patients with type 2 diabetes failing to achieve glycemic control on basal insulin in the USA. J Med Econ 2017;20:663-70.

43 Hunt $B, Y e$ Q, Valentine WJ, et al. Evaluating the long-term costeffectiveness of daily administered GLP-1 receptor agonists for the treatment of type 2 diabetes in the United Kingdom. Diabetes Ther 2017;8:129-47.

44 Ishii H, Madin-Warburton M, Strizek A, et al. The cost-effectiveness of dulaglutide versus insulin Glargine for the treatment of type 2 diabetes mellitus in Japan. J Med Econ 2018;21:488-96.

45 Kiadaliri AA, Gerdtham UG, Eliasson B, et al. Cost-utility analysis of glucagon-like peptide-1 agonists compared with dipeptidyl peptidase-4 inhibitors or neutral protamine Hagedorn basal insulin as add-on to metformin in type 2 diabetes in Sweden. Diabetes Ther 2014;5:591-607.

46 Kvapil M, Prázný M, Holik P, et al. Cost-effectiveness of IDegLira versus insulin intensification regimens for the treatment of adults with type 2 diabetes in the Czech Republic. Diabetes Ther $2017 ; 8: 1331-47$

47 Mittendorf T, Smith-Palmer J, Timlin L, et al. Evaluation of exenatide vs. insulin Glargine in type 2 diabetes: cost-effectiveness analysis in the German setting. Diabetes Obes Metab 2009;11:1068-79.

48 Psota M, Psenkova MB, Racekova N, et al. Cost-Effectiveness analysis of IDegLira versus basal-bolus insulin for patients with type 2 diabetes in the Slovak health system. Clinicoecon Outcomes Res 2017;9:749-62.

49 Ray JA, Boye KS, Yurgin N, et al. Exenatide versus insulin Glargine in patients with type 2 diabetes in the UK: a model of long-term clinical and cost outcomes. Curr Med Res Opin 2007;23:609-22.

50 Samyshkin Y, Guillermin A-L, Best JH, et al. Long-term cost-utility analysis of exenatide once weekly versus insulin Glargine for the treatment of type 2 diabetes patients in the US. J Med Econ 2012:15(Suppl 2):6-13.

51 Woehl A, Evans M, Tetlow AP, et al. Evaluation of the cost effectiveness of exenatide versus insulin Glargine in patients with sub-optimally controlled type 2 diabetes in the United Kingdom. Cardiovasc Diabetol 2008;7:24.

52 Zhang Y, McCoy RG, Mason JE, et al. Second-line agents for glycemic control for type 2 diabetes: are newer agents better? Diabetes Care 2014;37:1338-45.

53 Deng J, Gu S, Shao H, et al. Cost-effectiveness analysis of exenatide twice daily (BID) vs insulin Glargine once daily (QD) as add-on therapy in Chinese patients with type 2 diabetes mellitus inadequately controlled by oral therapies. J Med Econ 2015;18:974-89.

54 Gu S, Wang X, Qiao Q, et al. Cost-effectiveness of exenatide twice daily vs insulin Glargine as add-on therapy to oral antidiabetic agents in patients with type 2 diabetes in China. Diabetes Obes Metab 2017:19:1688-97.

55 Lasalvia P, Baquero L, Otálora-Esteban M, et al. Cost Effectiveness of Dulaglutide compared with liraglutide and glargine in type 2 diabetes mellitus patients in Colombia. Value Health Reg Issues 2017;14:35-40.

56 Tzanetakos C, Melidonis A, Verras C, et al. Cost-effectiveness analysis of liraglutide versus sitagliptin or exenatide in patients with inadequately controlled type 2 diabetes on oral antidiabetic drugs in Greece. BMC Health Serv Res 2014;14:419.

57 Ivanova A, Petrova G, Wrona W, et al. Modelling the long-term effect of diabetes therapy. An example with liraglutide. Comptes Rendus De L Academie Bulgare Des Sciences 2011;64:449-56.
58 Ericsson Åsa, Glah D, Lorenzi M, et al. Cost-effectiveness of liraglutide versus lixisenatide as add-on therapies to basal insulin in type 2 diabetes. PLoS One 2018;13:e0191953.

59 Hunt B, Glah D, van der Vliet M. Modeling the long-term costeffectiveness of IDegLira in patients with type 2 diabetes who are failing to meet glycemic targets on basal insulin alone in the Netherlands. Diabetes Ther 2017:8:753-65.

60 Chuang LH, Verheggen BG, Charokopou M, et al. Costeffectiveness analysis of exenatide once-weekly versus dulaglutide, liraglutide, and lixisenatide for the treatment of type 2 diabetes mellitus: an analysis from the UK NHS perspective. J Med Econ 2016;19:1127-34.

61 Lee WC, Conner C, Hammer M. Results of a model analysis of the cost-effectiveness of liraglutide versus exenatide added to metformin, glimepiride, or both for the treatment of type 2 diabetes in the United States. Clin Ther 2010;32:1756-67.

62 Petrova G, Ivanova A, Czech M, et al. Liraglutide vs. exenatide in combination with metformin and/or sulfonylurea therapy in type 2 diabetes mellitus therapy in Bulgaria: a modelling study. Comptes Rendus de L'Academie Bulgare des Sciences 2011;64:1507-14.

63 Valentine WJ, Palmer AJ, Lammert M, et al. Evaluating the long-term cost-effectiveness of liraglutide versus exenatide BID in patients with type 2 diabetes who fail to improve with oral antidiabetic agents. Clin Ther 2011;33:1698-712.

64 Zhang X, Liu S, Li Y, et al. Long-term effectiveness and costeffectiveness of metformin combined with liraglutide or exenatide for type 2 diabetes mellitus based on the core diabetes model study. PLoS One 2016;11:e0156393.

65 Hunt B, Vega-Hernandez G, Valentine WJ, et al. Evaluation of the long-term cost-effectiveness of liraglutide vs lixisenatide for treatment of type 2 diabetes mellitus in the UK setting. Diabetes Obes Metab 2017;19:842-9.

66 Hunt B, Kragh N, McConnachie CC, et al. Long-term costeffectiveness of two GLP-1 receptor agonists for the treatment of type 2 diabetes mellitus in the Italian setting: liraglutide versus Lixisenatide. Clin Ther 2017;39:1347-59.

67 Mezquita-Raya P, Ramírez de Arellano A, Kragh N, et al. Liraglutide versus Lixisenatide: long-term cost-effectiveness of GLP-1 receptor agonist therapy for the treatment of type 2 diabetes in Spain. Diabetes Ther 2017;8:401-15.

68 Tzanetakos C, Bargiota A, Kourlaba G, et al. Cost effectiveness of exenatide once Weekly versus insulin Glargine and liraglutide for the treatment of type 2 diabetes mellitus in Greece. Clin Drug Investig 2018;38:67-77.

69 Chakravarty A, Rastogi M, Dhankhar P, et al. Comparison of costs and outcomes of dapagliflozin with other glucose-lowering therapy classes added to metformin using a short-term cost-effectiveness model in the US setting. J Med Econ 2018;21:497-509.

70 Hunt B, Mocarski M, Valentine WJ, et al. IDegLira versus insulin Glargine U100: a long-term cost-effectiveness analysis in the US setting. Diabetes Ther 2017;8:531-44.

71 Geng J, Yu H, Mao Y, et al. Cost effectiveness of dipeptidyl peptidase-4 inhibitors for type 2 diabetes. Pharmacoeconomics 2015:33:581-97.

72 Klonoff DC, Schwartz DM. An economic analysis of interventions for diabetes. Diabetes Care 2000;23:390-404.

73 Raikou M, McGuire A. The economics of screening and treatment in type 2 diabetes mellitus. Pharmacoeconomics 2003;21:543-64.

74 Seuring T, Archangelidi O, Suhrcke M. The economic costs of type 2 diabetes: a global systematic review. Pharmacoeconomics 2015;33:811-31.

75 Singh K, Chandrasekaran AM, Bhaumik S, et al. Cost-effectiveness of interventions to control cardiovascular diseases and diabetes mellitus in South Asia: a systematic review. BMJ Open 2018:8:e017809.

76 Walker IF, Garbe F, Wright J, et al. The economic costs of cardiovascular disease, diabetes mellitus, and associated complications in South Asia: a systematic review. Value Health Reg Issues 2018;15:12-26.

77 Waugh N, Cummins E, Royle P, et al. Newer agents for blood glucose control in type 2 diabetes: systematic review and economic evaluation. Health Technol Assess 2010;14:1-248.

78 Zhang P, Engelgau MM, Norris SL, et al. Application of economic analysis to diabetes and diabetes care. Ann Intern Med 2004:140:972-7.

79 Zhong Y, Lin P-J, Cohen JT, et al. Cost-utility analyses in diabetes: a systematic review and implications from real-world evidence. Value Health 2015;18:308-14.

80 O'Mahony JF. The limitations of Icers in screening interventions and the relative net benefit alternative. Value Health 2015;18:A705. 
81 Hoch JS, Dewa CS. Advantages of the net benefit regression framework for economic evaluations of interventions in the workplace: a case study of the cost-effectiveness of a collaborative mental health care program for people receiving short-term disability benefits for psychiatric disorders. J Occup Environ Med 2014;56:441-5.

82 Willan AR. Incremental net benefit in the analysis of economic data from clinical trials, with application to the CADET-Hp trial. Eur $J$ Gastroenterol Hepatol 2004;16:543-9.
83 Willan AR, Lin DY. Incremental net benefit in randomized clinical trials. Stat Med 2001;20:1563-74.

84 Suranovic SM. Problems and extensions of PPP. International finance theory and policy. Available: http://internationalecon.com/ Finance/Fch30/F30-4.php [Accessed 24 Jan 2020].

85 Burdick C, Fisher L. Social security cost-of-living adjustments and the consumer price index. Soc Secur Bull 2007;67:73-88.

86 Pigou AC. The foreign exchanges. Q J Econ 1922;37:52-74. 